\title{
Penalidades Disciplinares
}

\section{Alberto Bonfim}

I - Necessidade de Apuração das Faltas:

a) no S.P.F. há sempre irregularidades: limpeza da máquina;

b) quem pode punir: autoridades, dirigentes, chefes;

c) como punir: grau das penas, conforme a falta;

d) por que punir: nem sempre punir é do bom dirigente;

e) resultados das puniçóes, escarmento, correção;

f) como apurar: meios sumários, sindicância, inquérito;

g) por que apurar: elemento para defesa ou recurso.

II - Elenco das Sanções Disciplinares:

a) advertência: não mais existe como pena;

b) repreensão: por escrito, tipo de faltas em que cabe;

c) suspensão: falta grave, reincidência, mais de 30 dias;

d) multa: não é de caráter geral;

e) destituição de função: falta de exação, chefia, comissão;

f) demissão simples e qualificada (causa da penalidade);

g) cassação de aposentadoria e disponibilidade, quando cabe.

III - Responsabilidade:

a) administrativa (punição disciplinar);

b) civil (indenização do dano, pode ser 1 décimo do vencimento):

c) penal (prisão e multa, 2 anos de reclusão e 4 de detenção: perda do cargo);

d) independência (uma não exclui a outra). 
I-a - Nos agrupamentos humanos, seja numa fábrica, seja numa caserna, seja num colégio, seja numa aldeia, numa vila, numa cidade, e mesmo numa nação, nem todos os componentes se comportam de acôrdo com as regras de bom viver para harmonia geral. Daí as normas (Códigos, Regulamentos, Regimentos) para disciplinar a conduta dos cidadãos. Essa regra não poderia falhar relativamente às repartições públicas. Daí a necessidade do regime disciplinar, que, entre nós, é um dos títulos do Estatuto dos Funcionários.

Como o país vem-se desenvolvendo, seja em progresso técnico, seja em população, cada vez mais se criam órgãos governamentais e, em conseqüiência, as repartições proliferam. Já somos mais de 1 milhão de funcionários públicos civis federais em todo o país. Já temos, por isso, necessidade de um Código Disciplinar, regido por uma Justiça Administrativa, para controlar o seu cumprimento.

Cada uma das três fôrças armadas (Exército, Marinha e Aeronáutica), com menor contingente do que as repartições públicas civis, tem um Regulamento Disciplinar sob o contrôle de Auditorias e tôdas sujeitas a um Tribunal Militar mais elevado. Isso significa o zêlo normal da Disciplina entre os homens de farda.

Muito mais necessária se faz uma Justiça organizada para os funcionários civis, muito mais numerosos, os quais devem ter não apenas um título estatutário para o seu regime disciplinar, mas um verdadeiro Código Disciplinar.

A máquina administrativa não pode funcionar sem sua aparelhagem completa, sem sua regulagem e limpeza periódicas. Num futuro que se espera não esteja muito distante, uma comissão de juristas do Direito Administrativo será oficialmente incumbida de preparar o Código Disciplinar dos Servidores Públicos Civis $\mathrm{Fe}$ derais e organizar a respectiva Justiça.

I-b - O poder disciplinar atualmente está com as autoridades, os dirigentes e os chefes de repartição em geral, de acôrdo com o art. 210 do E.F., na forma dos respectivos regimentos ou regulamentos.

Parece que êsse poder é intransferivel, dentro das faixas de punição, conforme a gravidade das faltas.

Embora, dentro do principio de que "quem pode o mais pode o menos", a autoridade competente para aplicar penalidade mais alta, possa aplicar, também, a mais baixa, afigura-se inadequado, 
atualmente, êsse principio para as penas disciplinares, face à $\mathrm{Re}$ forma Administrativa (Lei $n^{\circ}$ 200/67), que criou a delegação de podêres.

Ora, se a tendência é aliviar as mais altas autoridades, de tarefas executáveis pelas menos elevadas, como sobrecarregar aquelas, se estas as podem executar? Quando o E.F. fala em chefes de repartição (art. 210, III), parece que não se refere pròpriamente a chefes de seção, mas a dirigentes de órgãos com chefias hieràrquicamente abaixo. Daí por que não são os chefes de seção normalmente competentes para punir na forma dos regulamentos.

Embora as punições, geralmente, se originem das propostas dos chefes de seção, afigura-se salutar que as autoridades mais altas as apliquem. É que não convém aos Chefes de Seção punir pessoalmente os funcionários, pois com êles lidam diretamente.

Cabe, pois, evitar desavenças, às vêzes, de conseqüências imprevisíveis.

I-c - - Na aplicação das penas se leva em conta a gravidade da falta, bem como os danos que dela advierem para o serviço (art. 202 do E.F.).

O E.F. não define as espécies de faltas menores que as puniveis com demissão para efeito de gradação.

A repreensão se aplica por desobediência, falta de cumprimento dos deveres e negligência, mas o E.F. não define, nem exemplifica essas faltas.

É bem verdade que o E.F. registra vários deveres dos funcionários (art. 194), mas não é taxativo quanto à pena corresdente, podendo ser mais elevada que a repreensão, conforme a gravidade ou o dano.

De sorte que são arbitrárias as penas de repreensão, suspensão e destituição de função; dependem objetivamente dos casos concernentes que aparecem, e, subjetivamente, da maior ou menor drasticidade do dirigente.

I-d - As punições não devem ser aplicadas como vingança (ou represália). Não devem ser, também, aplicadas por prazer, porque ai se revela o sadismo do dirigente.

Quando o dirigente pune, não deve estar irado (ou exaltado). A punição é um dever, para servir de exemplo aos demais funcionários, para evitar a reincidência e para firmar a autoridade. 
Nem sempre aplicar punições, a torto e a direito, define o bom dirigente. Pode parecer, à primeira vista, que o dirigente que está sempre a punir, e que se torna temivel por isso, é um bom chefe.

O dirigente ideal é aquêle que organiza o serviço de tal forma que dificilmente os funcionários cometem faltas, ou escolhe as chefias que lhe estejam subordinadas de maneira que a disciplina se mantenha quase sempre intacta. Chefes arbitrários que lidam aos berros com seus subordinados, que sempre lhes estejam chamando a atenção descortêsmente, formam um ambiente propício à indisciplina. O bom dirigente tem de saber que a cooperação vale mais que a imposição. Impor, traz quase sempre a obediência cega, por temor, e não o salutar interêsse pelo trabalho. Os dirigentes de que o pais precisa para impulsionar a máquina administrativa não são aquêles que se calam quando tudo vai bem e só se manifestam para criticar, muitas vêzes àsperamente, o que esteja errado.

Tais dirigentes são nocivos ao desenvolvimento do país e devem ser afastados das funções de mando.

Os dirigentes úteis são aquêles que fiscalizam indiretamente, fazendo visitas periódicas às seções e tentam, também, uma palavra de estímulo para cada funcionário que cumpra o seu dever, buscando-lhe a cooperação.

Quando achar algo errado, o dirigente deve censurar com cortesia, pelo menos quando o funcionário erre involuntàriamente; e só punirá, quando outros meios, inclusive a mudança de tarefas para melhor aproveítamento vocacional, resultarem negativamente.

I-e - As punições, quando aplicadas com as cautelas retroreferidas, são salutares. O servidor punido não deve contar com a solidariedade dos colegas que sejam tidos por bons funcionários.

É preciso que o dirigente, ao puni-lo, leve em conta que qualquer bom funcionário, no seu lugar, não deixaria de aplicar-lhe sanção. Êsse consenso é necessário para que o dirigente não seja considerado injusto, tirano ou arbitrário.

Como já foi dito, a punição é, ao mesmo tempo, correção (do faltoso) e escarmento (para os outros). Se a falta fôr tal que, não punida, outros se vejam encorajados a praticá-la, haverá, fatalmente, o caos na disciplina interna da repartição.

Como escarmento (para servir de exemplo) a pena tem que se revestir da legalidade; a pena aplicada ilegalmente traz a 
revolta, não apenas do punido, mas, também, dos demais funcionários.

Há que ser, também, proporcional à falta. Pena excessivamente rigorosa traz os mesmos inconvenientes. Se o funcionário pode ser apenas repreendido, não se deve suspendê-lo. Se pode ser suspenso por 5 ou 10 dias, não se deve suspendê-lo por 20 ou 30 dias, e muito menos, por 60 ou 90 dias.

O dirigente há que ter em vista, também, o lado econômico do funcionário: a suspensão por trinta dias retirará todo o vencimento do punido por todo um mês; assim, se a falta puder ser corrigivel com suspensão de 3 a 8 dias, por que suspender por 30 dias?

Outro aspecto que o dirigente deve ter em vista é não prejudicar o serviço; dai poder suspender com multa, hipótese em que o funcionário continua trabalhando, com redução da metade do seu vencimento.

I-f - Quando a penalidade a aplicar, desde logo se verifica não ir além de uma suspensão trintidial, a apuração pode ser por meios sumários, sem necessidade de inquérito regular; não cabe à autoridade preocupar-se com faltas de pouca monta. "De minimis non curat praetor."

Demais, essa medida viria evitar que 4 servidores ( 3 membros da c.i. e mais o respectivo Secretário) sejam desviados de suas tarefas normais para apurar, regularmente, faltas não tão graves.

Quando à autoridade vieram denúncias sôbre as quais recaiam dúvidas quanto à sua gravidade ou quanto à sua veracidade, cabe-lhe mandar, por pessoa de sua confiança, sindicar, prèviamente, a respeito.

Não é salutar para a administração abrir logo inquérito sôbre denúncias falsas ou exageradas, partidas de eventuais suspeitos. O funcionário, quiçá inocente, ficará muito chocado com um inquérito para the apurar denúncias. Vir-lhe-á, irremediàvelmente, o desestímulo, a má vontade de cooperar e a descrença no reconhecimento do seu esfôrço.

A sindicância é sempre sigilosa, sem estardalhaço nem aparato e, preferentemente, sem peça escrita da colheita de informações. O sindicante, colhidas as informaçóes, poderá relatar, por escrito, em caráter confidencial à autoridade, o que tiver sabido sôbre o assunto. 
Se a autoridade chegar à convicção de que os fatos são reais e graves. instaurará, imediatamente, o inquérito. Se não, arquivará, mediante despacho circunstanciado, o assunto, sem deixar perceber ao sindicado e às demais pessoas o conteúdo das informações.

$\mathrm{Se}$ o assunto envolver irregularidades ocorridas em mais de um setor de atuação do sindicado, a autoridade poderá determinar a investigação (sigilosa) por mais de um sindicante.

Quando as irregularidades são notórias ou a denúncia oferecer dados concretos (datas, números, nomes, valôres...), não é lícito à autoridade admitir a notícia como falsa ou exagerada. Deve, então, desde logo, instaurar o inquérito, com todos os seus ritos de apuração, instrução e defesa.

I-g - A apuração de irregularidade no serviço público tem três finalidades: $1^{\text {a }}$ ) verificar a extensão - muitas vêzes a denúncia, ou o conhecimento direto das irregularidades, pressupõe a participação de um ou alguns indiciados, quando, por vêzes, há cutros que só a apuração regular pode revelar; $2^{\text {a }}$ ) fazer justiça - só mediante o conhecimento, pela perquirição, é que se revela a gravidade dos ilícitos, proporcionando a pena adequada; $3^{\text {i }}$ ) facilitar a defesa - no status de cidadão, não se lhe nega a defesa, devendo, pois, ser facilitada pelo conhecimento exato daquilo de que o acusado é incriminado.

II -a - A pena de advertência, prevista no E.F. anterior, foi expungida do atual. Hoje não mais constitui penalidade no seu sentido legal. Pode sê-lo em sentido estritamente moral, quando o chefe ou dirigente admoesta o funcionário sôbre determinado aspecto que não vem sendo observado normalmente. Mas não o é por escrito e sim apenas verbalmente, como corretivo de rotina, sem as conseqüências de uma punição escrita e publicada, que lhe iria macular a fôlha de assentamento, como antes.

II-b - A repreensão, sim, já é uıma penalidade no sentido juridico, por isso que, por escrito e publicada para conhecimento de todos («erga omnes»). Cabe aplicá-la por faltas relativamente leves, mas que possam adquirir gravidade ou reincidência se não forem coibidas. Por exemplo: desobediência, falta de cumprimento dos deveres e negligência, tôdas elas em prejuizo do ritmo do serviço. O art. 194 do E.F. traz o elenco dos deveres, cuja transgressão, sem reincidência, acarreta normalmente a pena de repreensão. 
II-c - A pena de suspensão se aplica nos casos de falta grave e reincidência. Definimos a falta grave como "todo o ato irregular, praticado de modo a prejudicar sensivelmente os objetivos legais da repartição e a servir de mau exemplo aos companheiros de trabalho" (O Processo Administrativo, 9a ed., Freitas Bastos, pág. 58). Tal definição representa um esfôrço para tornar mais compreensível a significação dessa falta, à máquina de conceito legal. Têm-se entendido como puniveis com suspensão as faltas previstas no art. 195, I, II e III, do E.F.

A reincidência, para efeito de suspensão (art. 205, in fine, do E.F.), há que ser sempre especifica, isto é, já estar punido com repreensão pela mesma falta anteriormente praticada. A reincidência genérica é o cometimento de falta de natureza diversa, já tendo havido punição anterior, mesmo que aquela tenha acarretado a pena de repreensão, não se deve punir com a suspensão, desde que não seja grave, mas, sim, com outra repreensão. A pena de suspensão até um trintídio prescinde do inquérito, podendo ser aplicada, mediante apuração sumária. Tanto na repreensão, como na suspensão, até 30 dias, é aconselhável fazer constar da respectiva portaria, tantos considerandos quantos forem necessários para caracterizar a natureza da falta e suas circunstâncias. Isso proporcionará oportunidade de defesa e eventual recurso, o que representa um direito do acusado.

II-d - A pena de multa se aplica em determinados casos muito restritos, dependendo sempre de regulamento ou regimento que disponha a respeito.

Essa penalidade pode resultar, igualmente, da transformação da de suspensão. Às vêzes, um chefe ou dirigente se vê na contingência de suspender um subordinado. Mas os tem em número reduzido ou as tarefas afetas ao seu setor são tantas que o punido, durante a suspensão, faria falta. Então, pode êle determinar que o funcionário trabalhe, percebendo, apenas, a metade do vencimento ou remuneração, durante o periodo punitivo. A isso se chama de "conversão da suspensão em multa."

II-e - A destituição de função é penalidade, sòmente, aplicável aos detentores de função gratificada, por falta de exação no cumprimento do dever e acarretando a perda dessa função. Exação significa "fazer executar." Ora, a falta de ordem para executar é função de mando. Quem ordena é o chefe e quem executa são os funcionários. Assim, um setor que não funciona ou funciona mal é porque o respectivo encarregado (dirigente ou 
chefe) não dá as ordens necessárias. É caso de aplicação da pena de destituição da função.

Pela mesma razão, o detentor de cargo de direção poderia ser destituído do cargo em comissão, conservando o cargo efetivo em caso de falta de exação. Mas, assim, não tem entendido a administração que prevê para êles a demissão, naturalmente, devido a exercerem cargo (e não função) de confiança.

Porém, o sentido é o mesmo. Uma interpretação menos literal da lei, no futuro, poderia consagrar a pena de destituição do cargo de confiança, conservando o titular seu cargo efetivo, assim como o ocupante de função gratificada perde, em sendo destituído, sua comissão, conservando seu cargo efetivo.

II f - A pena de demissão pode ser simples ou qualificada.

Não é pena corretiva, mas, expulsiva. A demissão qualificada é a que vem acompanhada da cláusula agravante "a bem do serviço público"; algumas são automáticas, porque decorrem da própria gravidade do ilícito. As simples podem tornar-se qualificadas, a critério da autoridade julgadora, tendo em vista as circunstâncias que envolvam a irregularidade (art. 209, do E.F.).

$\mathrm{O}$ art. 207 do E.F., reportando-se, também, a itens do artigo 195, traz o elenco das irregularidades puniveis com demissão, aliás, tôdas previstas no Código Penal (arts. 312 a 326), embora com nomes diversos, a maioria das vêzes (Ver nosso Manual, "O Processo Administrativo", 9a edição, pág. 68).

$\mathrm{O}$ art. 208 do E.F. manda fazer figurar do ato de demissão a causa da penalidade. Parece que não basta apenas citar o dispositivo violado.

Afigura-se que a lei quis ir além, no sentido escarmentativo, deixando claro a todos, por que um servidor foi punido expulsivamente.

Infelizmente, o E.F. não prevê a subsistência dos dependentes em caso de penalidade expulsiva. Um funcionário passa 20,30 ou mais anos a serviço do Estado, compulsòriamente, contribuindo para a previdência e, depois, na desdita de cometer alguma irregularidade, ser demitido, além de perder o cargo e o respectivo vencimento, bem como tôda a contribuição previdenciária. Isso até parece apropriação indébita do Orgão de Previdência. Fizemos projetos e sugestes para corrigir essa injustiça, mas só foram contemplados os beneficiários dos demitidos por Atos Institucionais. 
No futuro, oxalá a legislação se torne mais humana com os familiares dos funcionários, os quais nada têm com as eventuais irregularidades que êstes pratiquem. Em Portugal, por exemplo, o funcionário que comete irregularidade é aposentado já que contribui para a aposentadoria, como na Inglaterra. Entre nós, ao menos, a pensão para os beneficiários devia haver, já que para isso sofre desconto em seu vencimento.

Do decreto de demissão há que constar sempre o número do processo a que haja respondido, com direito a ampla defesa.

II-g - A cassação da aposentadoria e a cassação da disponibilidade são penas aplicáveis aos que, na atividade, praticaram ilícitos pelos quais seriam demitidos ou pelos motivos mencionados no art. 212, II, III, IV e parágrafo único. Pela mesma razão que não se deve conceder exoneração ao que responda a inquérito administrativo até a verificação de sua eventual inocência, parece que, nas mesmas condições, não se deve aposentá-lo, exceto compulsòriamente. Não seria interessante, aposentá-lo, para depois cassar-lhe a aposentadoria.

Preferentemente, se cassa a aposentadoria, quando, sòmente, após a concessão desta, se verifica haver o servidor cometido ilicito que lhe acarretaria demissão, se ainda em atividade. E' uma pena desvinculativa.

A disponibilidade está hoje restrita aos casos de extinção de cargos sem possibilidade de imediato aproveitamento em outro equivalente. Se nesse estado ficar provado que o funcionário praticou ilícito grave quando em atividade (ou após o término dela), punivel com demissão, cassa-se-lhe a disponibilidade. São penas desvinculativas a cassação da aposentadoria e a cassação da disponibilidade, face à perda dos respectivos proventos.

III-a - A responsabilidade administrativa decorre da culpa ou dolo nas irregularidades, tendo-se em vista, também, sua gravidade, para efeito da pena disciplinar. Nessa responsabilidade se tem em vista que ao funcionário não é lícito infringir o E.F. quanto aos deveres e às proibições. A falta de vigilância que leva o funcionário a violar essas proibições ou êsses deveres é que constitui a responsabilidade administrativa. A responsabilidade é tanto maior quanto maior fôr a autoridade.

Uns estão mais sujeitos que outros a cometer irregularidades, seja infringindo deveres, seja violando proibições. Por exemplo, o fiscal de renda ou de consumo, mais ligado ao comércio e à indústria, são mais tentados a receber propinas do que o buro- 
crata; o policial que, diretamente, lida com os marginais está mais sujeito a tomar-lhes objetos (armas, principalmente) com apropriação indébita ou a relaxar prisões, mediante propinas.

Assim, também, os repressores de contrabando, os controladores de preços, os inspetores do trabalho e semelhantes. Mas, todos são iguais perante essa responsabilidade. De sorte que cabe ao dirigente ou ao chefe de equipe alertar sempre os seus auxiliares sôbre a tentação a que se expõem e sôbre sanções concernentes.

III-b - A responsabilidade civil decorre do dever funcional de indenizar o dano causado à Fazenda Nacional. Neste caso, também, se inclui o particular (não servidor público). A Administração deve promover a cobrança amigável ou judicial do que lhe pertence e que tenha sido subtraido ou danificado pelo servidor ou pela parte. Nos casos de culpa ou dolo do servidor, ainda que o autor ou beneficiário do dano seja um terceiro, cabe àquele indenizá-lo, reservando-se-lhe o direito regressivo contra o particular.

Por exemplo, se uma camioneta oficial é cedida, irregularmente, a um terceiro que a furte ou danifique, o funcionário cedente terá que cobrir o prejuizo, embora possa, depois, em ação própria, pleitear a indenização do quantum contra êsse terceiro. $\mathrm{Na}$ indenização do dano, poderá a Administração cobrar do funcionário, na base do desconto de 1 décimo do vencimento, no que exceder a fiança, quando esta fôr exigivel.

No dano causado a terceiro, a Administração o indeniza, cabendo direito regressivo desta contra o eventual funcionário causador do prejuizo.

III-c - A responsabilidade penal se refere ao cuidado que o funcionário precisa ter no serviço para não ser criminalmente processado, podendo ser condenado à prisão e multa. Essa responsabilidade pode acarretar ao funcionário a perda do cargo, se condenado a 4 anos de detenção ou a 2 anos de reclusão, ainda que não responda a processo administrativo ou dêste não resulte demissão. Basta êsse lapso de tempo de condenação para, nas duas hipóteses, haver, automàticamente, a perda do cargo.

$\mathrm{Na}$ detenção o condenado está sujeito à prisão em comum com os outros presos, e na reclusão está sujeito à disciplina militar, com isolamento.

III-d - As instâncias civil, penal e administrativa são independentes, de modo que podem cumular-se, sem se poder argu- 
mentar que o funcionário esteja sendo duplamente punido (bis in idem).

Não há confundir a prisão administrativa com a prisão punitiva; nem a suspensão preventiva com a suspensão disciplinar. A primeira é praticada pela administração e a segunda, pela esfera penal; a terceira é medida acauteladora, e a quarta, penalidade corretiva; estas duas últimas praticáveis pela própria Administração.

Não cabe, também, confundir a prisão administrativa com a prisão preventiva: ambas são medidas acauteladoras; aquela adotável pela Administração; esta é aplicável pelo Juizo Criminal.

Entretanto, a jurisprudência já sedimentada indica que há repercussão do julgado criminal sôbre a decisão administrativa, quando a esfera penal proclama o êrro de pessoa ou a inexistência do fato.

AlberTo BonfiM - Assistente Juridico do DASP. 